RESEARCH ARTICLE

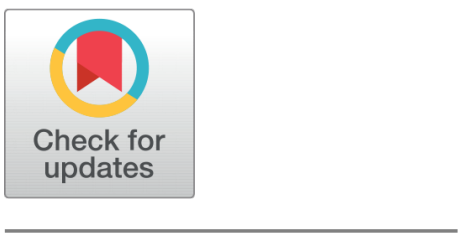

OPEN ACCESS

Received: 18.04.2021

Accepted: 27.05.2021

Published: 02.07.2021

Citation: Anh ATHT, Quyen NV (2021) Energy - Efficient Operation in Subway Systems: Tracking Optimal Speed Profile with on Board Supercapacitor Energy Storage System. Indian Journal of Science and Technology 14(23): 1914-1928. https://doi.org/ 10.17485/IJST/v14i23.602

* Corresponding author. quyen.nguyenvan@hust.edu.vn Funding: None

Competing Interests: None

Copyright: (c) 2021 Anh \& Quyen. This is an open access article distributed under the terms of the Creative Commons Attribution License, which permits unrestricted use, distribution, and reproduction in any medium, provided the original author and source are credited.

Published By Indian Society for Education and Environment (iSee)

ISSN

Print: 0974-6846

Electronic: 0974-5645

\section{Energy - Efficient Operation in Subway Systems: Tracking Optimal Speed Profile with on Board Supercapacitor Energy Storage System}

\author{
An Thi Hoai Thu Anh ${ }^{1}$, Nguyen Van Quyen ${ }^{2 *}$ \\ 1 Department of Electrical Engineering, University of Transport and Communications, Hanoi, \\ 112100 , Vietnam \\ 2 Department of Applied Mechanics, Hanoi University of Science and Technology, Hanoi, \\ 112100 , Vietnam
}

\section{Abstract}

Objectives: To verify the energy efficiency operation of electrified trains on the certain metro line, in Vietnam by combining two solutions to recover regenerative braking energy with on-board supercapacitors and tracking the optimal speed profile. Methods: This study proposes an integrated optimization method: applying Pontryagin's maximum principle (PMP) finds the optimal speed profile with fixed running time and recuperating regenerative braking energy by designing the control method - Current Mode Control (CMC) to manage charge/discharge process of the on-board supercapacitor energy storage system (SCESS) tracking the optimal speed profile. Findings: With this approach, a considerable reduction in consuming energy obtained for Cat Linh-Ha Dong metro line, Vietnam has been verified by simulation results on MATLAB and MAPLE software indicating that applying PMP, the highest operation energy saving is $10.15 \%$, but if both solutions PMP and SCESS are applied, the energy saving level increases up to $14.7 \%$ in comparison with simulation results of the case of original speed profile. Novelty: Combining two energy saving solutions simultaneously: applying PMP to determine the optimal speed profile and using super-capacitors with CMC algorithm have recuperated the regenerative braking energy. The level of energy saving is higher than other saving solutions.

Keywords: Pontryagin's Maximum Principle; Supercapacitor Energy Storage System; Current Mode Control; EnergyEfficiency Operation; Timetable Optimization

\section{Introduction}

While subway systems, as an important part of urban transport, carry passengers to their destination safely, quickly, and conveniently, they also consume a lot of energy; namely, $40 \%$ to $50 \%$ of the total energy consumed is for traction power ${ }^{(1)}$. Therefore, the studies of energy-saving in electric railways have an important economic value, 
many energy saving methods have been published by researchers, manufacturers worldwide, typically in recuperating regenerative braking being able to reach up more than $30 \%$ of the traction energy ${ }^{(2)}$. Surplus energy in braking phases recovered by the installation of onboard or wayside energy storage systems with designing controllers to control charge/discharge process of SCESS suitable for operation characteristic of train. Studies, applications of super capacitor energy storage system with tested to practical utilization ${ }^{(2-16)}$. Iannuzzi et $\mathrm{al}^{(5)}$ using onboard SCESS integrated with traction drive system saves energy to $38 \%$, reducing peak power up to $50 \%$ in accelerating regime, stabilizing voltage on DC bus to $1 \%$, increasing power supply distance among traction substations ; Dominguez et al released a study of energy consumption reduction to $24 \%$ in the Metro de Madrid ${ }^{(7)}$; Michael Steiner et al ${ }^{(8)}$ shows Bombardier installed Mitrac energy saver being able to reduce the consumption of the traction energy to $30 \%$ and line current peak and voltage drop by $50 \%$; Diego Iannuzzi, Flavio Ciccarelli, Davide Lauria ${ }^{(12)}$ use stationary ultra-capacitor storage device for improving energy saving and voltage profile of light transportation networks; reversible substations ${ }^{(17,18)}$; maximizing the regenerative energy exchange between trains by synchronizing their accelerating and braking phases as much as possible ${ }^{(19-21)}$, Fathy Ahmed et al. ${ }^{(22)}$ applied parasitism-predation algorithm (PPA) in the energy management strategy for hybrid photovoltaic/fuel cell/battery/supercapacitor to minimize the hydrogen consumption of fuel cell; Jamadar Najimudin et al ${ }^{(23)}$ developed regenerative braking system (RBS) and braking energy management techniques, considering different driving situations and road conditions which employed in addition to mechanical braking for increasing the braking efficiency of the electric vehicle system. Additionally, another energy saving approach which has also attracted more attention from experts is to find optimal speed profile by two methods: the Mathematical and Optimal theory (Maximum principle, Dynamic programming, Linear programming); the other one is the Computational Intelligence (Fuzzy neural networks, Genetic Algorithm, Predictive control, Colony Optimization Algorithm) ${ }^{(24-26)}$. A group of scientists at the University of South Australia Howlett et al. ${ }^{(27,28)}, \mathrm{Vu}^{(29)}$, and Albrecht et al ${ }^{(30,31)}$ systematically have researched optimal strategies using mathematical approaches and optimal theory to propose control laws to detect optimal switching points, then finding the optimal speed profile, and others, Khmelnitsky ${ }^{(32)}$ attempted to solve the problem of optimal control by applying the Pontryagin's maximum principle and adjoint variables, which consider regenerative braking, Liu et al. ${ }^{(33)}$ uses the maximum principle for finding a set of optimal controls, the control switching graphs, and complementary conditions of optimality. Bao Huy et al. ${ }^{(34)}$ applied Pontryagin's minimum principle to develop an optimal energy management strategy (EMS) for battery/supercapacitor hybrid energy storage systems replaced Dynamic Programming (DP), and the proposed optimal EMS is hundreds of times faster than DP with better results. The novel strategy is based on formulating the problem in terms of power and energy which forms a state-constrained optimal control problem. PMP is then applied with a penalty function, in which the inequality state constraints are reformulated to deduce a new state-unconstrained problem. The proposed optimal EMS is hundreds of times faster than DP with better results. Moreover, the optimal solution is piecewise constant that could give significant insights to develop real-time strategies in future studies. Shaofeng $\mathrm{Lu}^{(35)}$ applied three optimization algorithms (Colony Optimization Algorithm, Dynamic Programming, GA) to search for the optimal speed trajectory, Dominguez et al. ${ }^{(36)}$ designed the speed profile giving guarantees of running time and consumption energy saving, then Dominguez et al. ${ }^{(7)}$ designed train operation speed profiles for an Automatic Train Operation System (ATO) to select the optimal speed profiles with reducing energy consumption, Wong and $\mathrm{Ho}^{\left({ }^{37}\right)}$ used genetic algorithm, Açikba, Söylemez ${ }^{(38)}$ utilized artificial neural networks and genetic algorithms to determine the optimal coasting point, yet all studies have not mentioned fixed running time, as well as combined solutions to enhance energy saving percentage in electric train operation. Therefore, in this paper, a combined approach between the optimal control theory-Pontryagin's maximum principle determining the optimal speed profile, fixed running time and the onboard supercapacitor energy storage system recuperating regenerative braking energy with charging or discharging of SCESS tracking the optimal speed profile is proposed.

\section{Urban Railway System Model}

Urban electric railway system in Figure 1 consists of parts: traction substations, overhead lines or the third rail, feeders, trains as electric loads, traction drive motors, and onboard supercapacitor energy storage system including a bank of supercapacitors with bidirectional DC-DC converter. Modelling some main parts has been performed briefly.

\subsection{Train model}

The train using Onboard supercapacitor energy storage system is represented by the following continuous - space model ${ }^{(39-41)}$

$$
\begin{aligned}
& \frac{d x}{d t}=v \\
& m v \frac{d v}{d x}=F_{t v}(v)+\frac{P_{s c}(t)}{v}-F_{b r}(v)-W_{0}(v)-F_{g r a d}(x)
\end{aligned}
$$




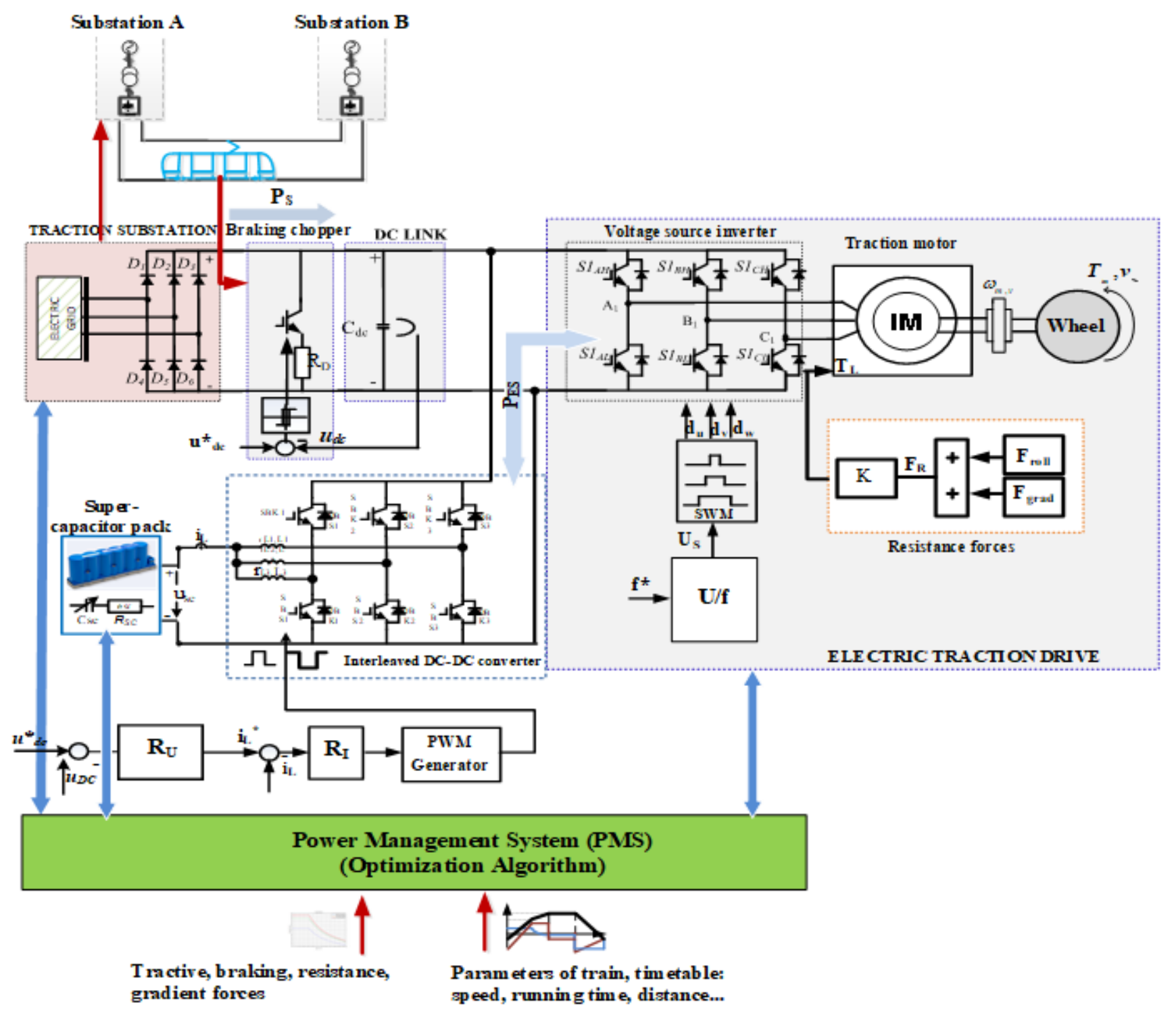

Fig 1. General control structure for energy consumption of single train operation

Where $\mathrm{v}, \mathrm{t}, \mathrm{x}, \mathrm{m}$ represent respectively train $\operatorname{speed}(\mathrm{m} / \mathrm{s})$, operation time $(\mathrm{s})$, train position $(\mathrm{m})$, full load translating mass of train (tone) and $F_{t r}, F_{b}, W_{0}, F_{\text {grad }}$ are traction, electrical braking, resistance, gradient resistance forces applied on the train. Furthermore, differing with the conventional continuous - space model of train is supercapacitor power $P_{s c}(t)$ in ences in body same as Equation (1) $P_{s c}(t)$ accumulating/releasing energy by charging/discharging of supercapacitors tracks operating characteristics of trains. Regenerative braking energy recuperation is possible when the electric train speed is greater than $10 \mathrm{~km} / \mathrm{h}$ in braking phase, while mechanical braking force only works at a speed less than $10 \mathrm{~km} / \mathrm{h}$ in braking phase energy recover the mechanical braking force is omitted in equation (1).

Figure 2 describes discharge/charge process of SCESS accordance with operation of trains in three phases. The SCESS's discharging energy supports for operating trains in accelerating regime with $P_{s c}(t)$ being negative; the SESSs do not charge/ discharge in coasting regime with $P_{s c}(t)$ equal to $0 \mathrm{~kW}$, and charging regenerative braking energy in braking regime with $P_{s c}(t)$ being positive. 


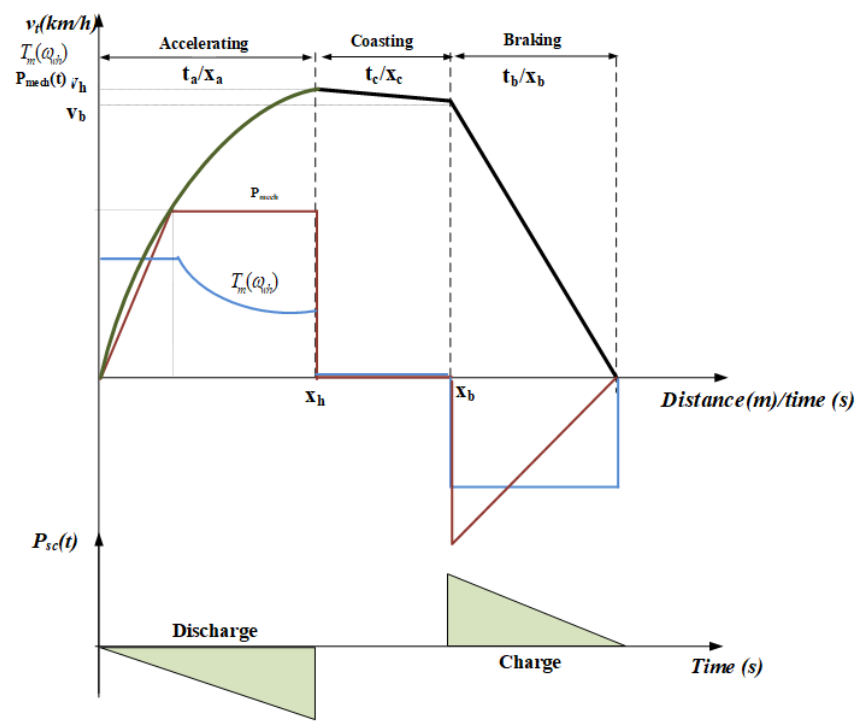

Fig 2. Characteristics of traction motor integrated with SCESS

\subsubsection{Traction, braking forces}

With characteristic curves of traction force, braking force performed by manufacturers, using the identification method: Least Square Method to find equivalent polynomials.

The maximum traction force corresponding to the speed is

$$
F_{t r}=\left\{\begin{array}{l}
13.2(0 \leq v \leq 32) \\
-2.5 \times 10^{-5} v^{3}+0.007 \times v^{2} \\
-0.66 v+28.35 \quad(32<v 80)
\end{array}\right.
$$

The maximum braking force corresponding to the speed is

$$
F_{b r}= \begin{cases}14.7 \quad(0 \leq v \leq 65) & \\ -0.254 v+31.21 & (65<v 75) \\ -0.2027 v+27.36 & (75<v 80)\end{cases}
$$

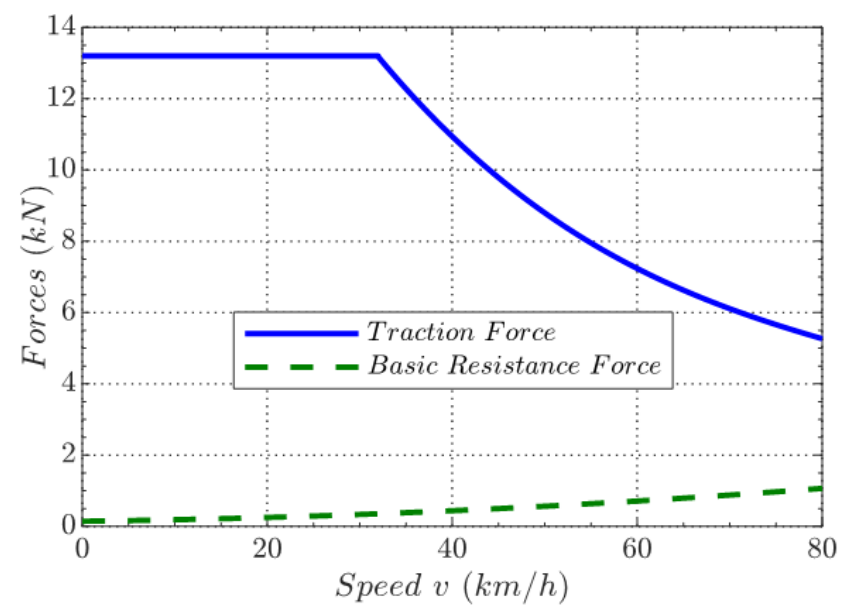

Fig 3. Maximum traction characteristic curve per motor 


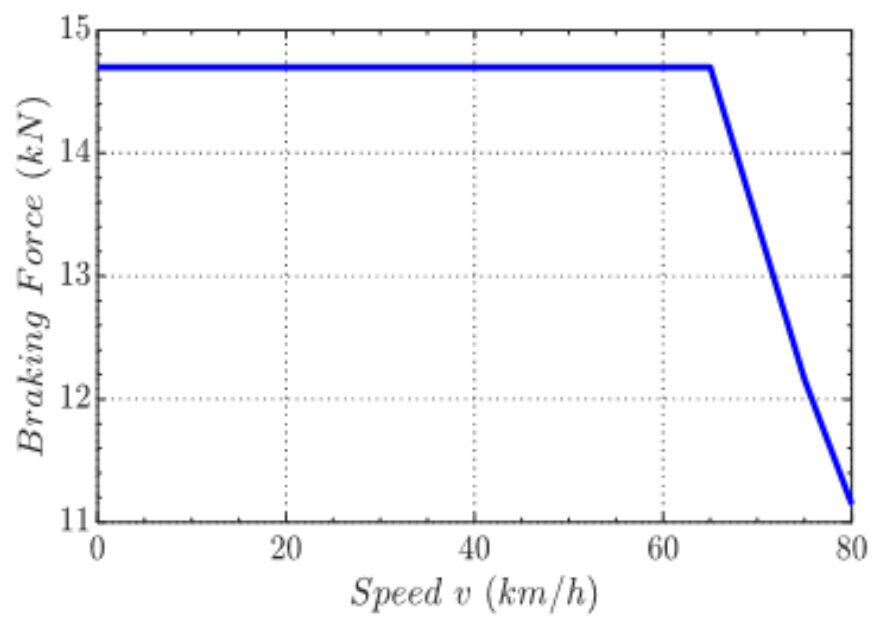

Fig 4. Maximum braking characteristic curve per motor

\subsubsection{Basic resistance, and gradient forces}

Forces acting on the train in which the basic resistance force $w_{0}(v)$ consisting of the air resistance, the friction resistance is represented in David's formula ${ }^{(42)}$.

$$
w_{0}=\frac{W_{0}}{m}=a+b v+c v^{2}
$$

Where a,b,c are coefficients of train's resistance force.

The gradient force $F_{\text {grad }}$ caused by slope of road

$$
F_{\text {grad }}=m g \sin \alpha
$$

Where g, a are the gravity acceleration and the rail track slope respective.

\subsection{Supercapacitor energy storage system mode}

The energy storage system consists of an interleaved bidirectional DC-DC converter with an on-board supercapacitor bank, as shown in Figure 5.

The DC-DC converter being able to exchange energy bi-directionally placed between high voltage DC bus and low voltage SCESS operates in buck or boost mode: In boost mode, SBS and DBS are the operating switches, and the low-voltage side delivers energy to the high-voltage side (DC bus); super-capacitor modules get discharged by low voltage. In buck mode, SBK and DBK are the operating switches, and the high voltage side transfers energy to the low voltage side; the super-capacitor modules get charged from the DC bus.

Averaged model of bidirectional DC-DC converter is shown in Figure 6, switches are replaced by an ideal transformer with $\mathrm{d}(\mathrm{t})$ being transformer factor, and $u_{1}(t)=d(t) u_{2}(t), i_{2}(t)=d(t) i_{1}(t)$

$$
\left\{\begin{array}{l}
L \frac{d i_{L}}{d t}=-r_{L} i_{L}+d u_{D C}-u_{S C} \\
C \frac{d u_{D C}}{d t}=-d i_{L}+i_{i n v}
\end{array}\right.
$$

\section{Control Design for Urban Railway System}

The target is to minimize train operation energy by two solutions: using PMP finds optimal speed profile, and using SCESS recovers regenerated braking energy; so does control design. 


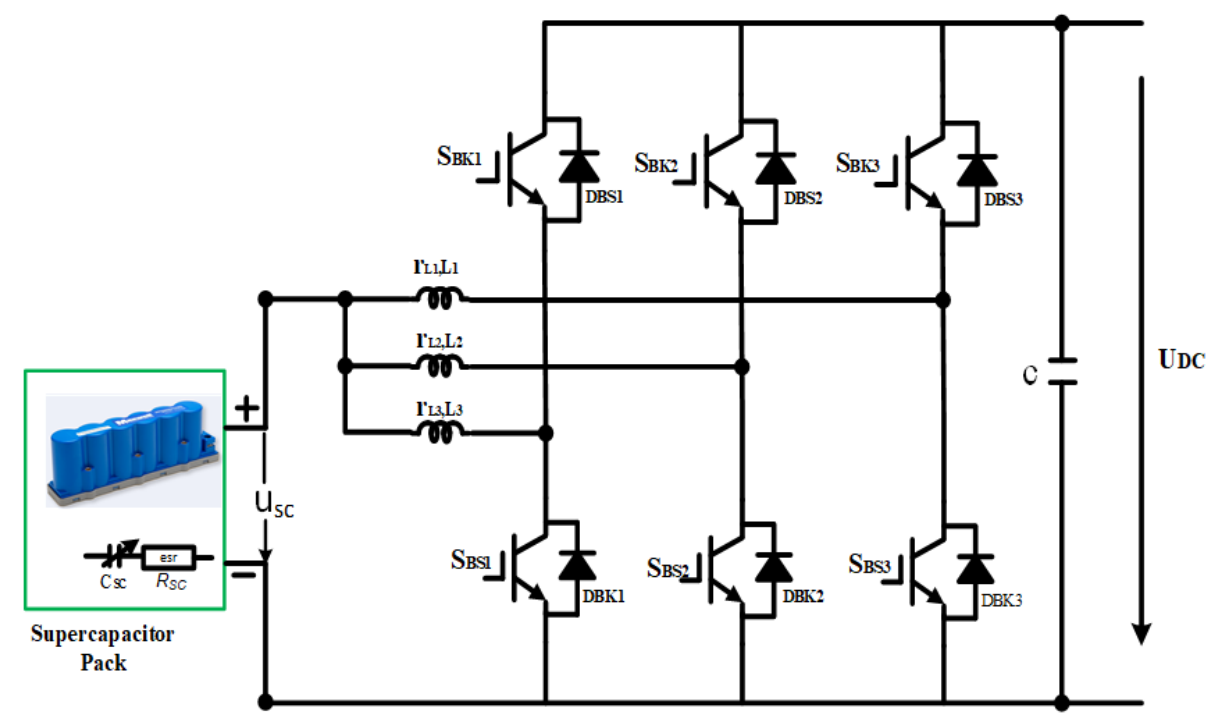

Fig 5. Power electric scheme of a three phase Interleaved DC-DC converter

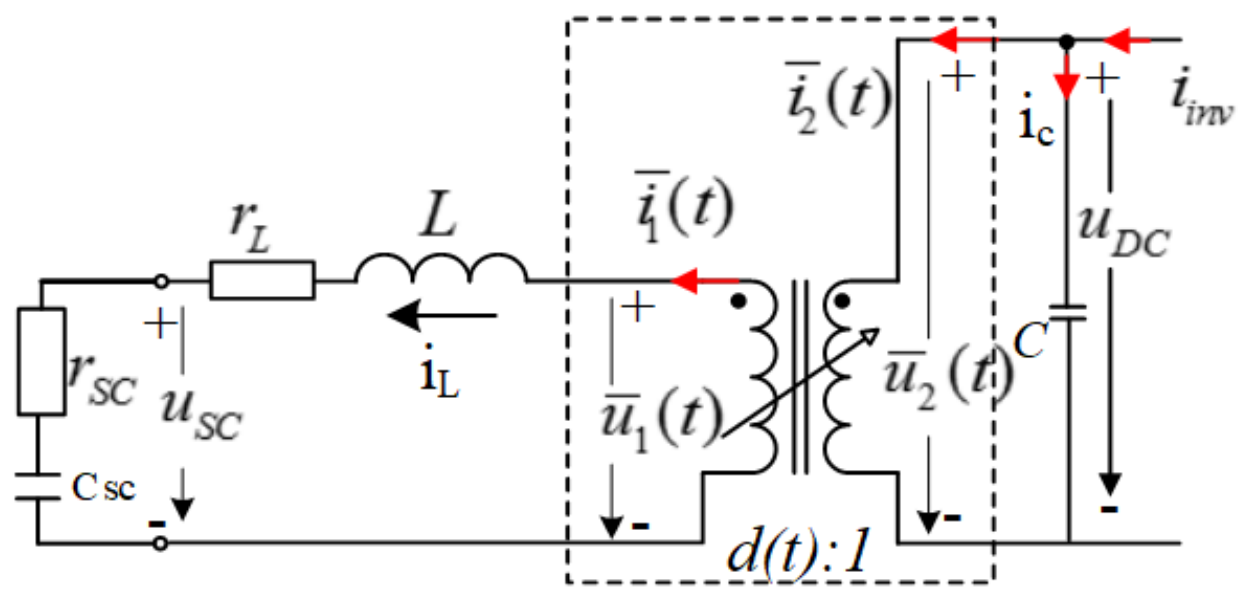

Fig 6. Equivalent circuit of averaged model of bidirectional DC-DC converter Averaged model of DC-DC bidirectional converter shown average model is ${ }^{(43)}$

\subsection{Optimal Speed Profile determination based on PMP}

Many solutions for the energy effective control are outlined to detect the optimal speed profile with minimizing train's operation energy consumption, ensuring fixed trip time as well. In the part 3, utilizing PMP computing optimal switching points of operation modes of speed trajectory applies for the train model recuperating regenerative braking energy by the onboard supercapacitor energy storage system.

\subsubsection{Problem formulation}

In proposed method, regenerative braking energy has recovered by SCESS. Train motion equation is rewritten:

$$
\left\{\begin{array}{l}
\frac{d t}{d x}=\frac{1}{v} \\
v \frac{d v}{d x}=u_{t r} f_{t r}(v)+\frac{p_{s c}(t)}{v}-u_{b r} f_{b r}(v)-w_{0}(v)-f_{\text {grad }}(x)
\end{array}\right.
$$


Where $u_{t r}, u_{b r}$ are defined traction and braking control variables of train, both of which are restrained by $u_{t r} \hat{\mathrm{I}}[0,1] ; u_{b r} \hat{\mathrm{I}}[0,1] ; f_{t r}, f_{b r}, f_{g \text { gad }}$ are forces per unit mass; traction force applied at the wheels, braking force, gradient force acting on the train.

Boundary conditions are given by

$$
\begin{gathered}
0 v(x) V(x) \\
\left\{\begin{array}{l}
v(0)=0 ; v(X)=0 \\
t(0)=0 ; t(X)=T
\end{array}\right.
\end{gathered}
$$

Where $\mathrm{V}(\mathrm{x})$ is the maximum allowable speed, $\mathrm{X}$ is the terminal of the train operation; $\mathrm{v}(0), \mathrm{v}(\mathrm{X})$ are the speed at the beginning, at the end of the route; $T$ is duration of the trip is also given by the timetable.

Assume that accelerating phase happens between $\left\{t_{1}, t_{2}\right\}$; coasting phase happens between $\left\{t_{2}, t_{3}\right\}$; regenerative braking phase happens between $\left\{t_{3}, t_{4}\right\}$, thus supercapacitor power per unit mass $p_{s c}(t)$ is given

$$
P_{s c}(t)=\left\{\begin{array}{l}
-p_{s c}(t) \quad t_{1} t t_{2}(\text { discharge time }) \\
0 \quad t_{2}<t t_{3}(\text { coastingtime }) \\
p_{s c}(t) \quad t_{3}<t t_{4} \quad \text { (charge time) }
\end{array}\right.
$$

To ensure absolute schedule time, objective function is defined as:

$$
J=\int_{0}^{x}\left[\mu_{t r} f_{t r}(v)+\frac{p_{s c}(t)}{v}\right] d x+\lambda T \rightarrow \min
$$

Where $T=T_{\text {actual }}(X)-T_{\text {demand }}(X), \lambda$ is an unknown Lagrange multiplier.

Given

$$
T_{\text {actual }}(x)=\int_{0}^{x} \frac{d x}{v}
$$

Finding the value of Lagrange multiplier $\lambda$ is to deliver the required running time $T_{\text {dem and }}(X), T_{\text {actual }}$ is actual running time of train.

Therefore, object function is

$$
J=\int_{0}^{X}\left[u_{y} f_{t}(v)+\frac{p_{x}(t)}{v}+\frac{\lambda}{v}\right] d x \rightarrow \min
$$

\subsubsection{Solution}

Pontryagin's Maximum Principle is applied to solve the train energy-efficient operation problem by seeking optimal switching points of the train's operation modes.

Combining (7)-(13), the Hamiltonian function can be expressed in the form as follow:

$$
H=-\left(u_{t r} f_{t r}(v)+\frac{p_{s c}(t)}{v}+\frac{\lambda}{v}\right)+p_{1} \frac{1}{v}+p_{2}\left(\frac{u_{t r} f_{t r}(v)+p_{s c}(t) / v-u_{b r} f_{b r}(v)-w_{0}(v)-f_{g r d}(x)}{v}\right)
$$

Where $p_{1}, p_{2}$ are adjoint variables. Adjoint variable differential equations are reformed:

$$
\begin{gathered}
\frac{d p_{1}}{d x}=-\frac{\partial H}{\partial t}=\frac{1}{v} \frac{d p_{s c}(t)}{d t}-\frac{p_{2}}{v^{2}}\left(\frac{d p_{s c}(t)}{d t}\right) \\
\frac{d p_{2}}{d x}=-\frac{\partial H}{\partial v}=\left[u_{t r} \frac{\partial f_{t r}}{\partial v}-\frac{p_{s c}}{v^{2}}-u_{b r} \frac{\partial f_{b r}}{\partial v}-\frac{\lambda}{v^{2}}\right]+ \\
\frac{p_{1}}{v^{2}}+\frac{p_{2}}{v^{2}}\left[u_{t r} f_{t r}(v)+p_{s c}(t) / v-u_{b r} f_{b r}(v)-w_{0}(v)-f_{\text {grad }}(x)\right] \\
-\frac{p_{2}}{v}\left[u_{t r} \frac{\partial f_{t r}}{\partial v}-\frac{p_{s c}}{v^{2}}-u_{b r} \frac{\partial f_{b r}}{\partial v}-\frac{\partial w_{0}}{\partial v}\right]
\end{gathered}
$$


Substitute $p=\frac{p_{2}}{v}$

$$
\begin{gathered}
\frac{d(p \cdot v)}{d x}=p \frac{d v}{d x}+v \frac{d p}{d x}=\frac{d p_{2}}{d x} \Rightarrow v \frac{d p}{d x}=\frac{d p_{2}}{d x}-p \frac{d v}{d x} \\
\left\{\begin{array}{l}
\frac{d p_{2}}{d x}=-\frac{\partial H}{\partial v} \\
\frac{d v}{d x}=\frac{u_{t r} f_{t r}+\frac{p_{s c}}{v}-u_{b r} f_{b r}-w_{0}-f_{\text {gral }}}{v}
\end{array}\right.
\end{gathered}
$$

Hamiltonian function is reformulated as:

$$
\begin{aligned}
& H=(p-1) u_{t r} f_{t r}+(p-1) \frac{p_{s c}}{v}-p u_{b r} f_{b r} \\
& -p\left(w_{0}+f_{\text {grad }}\right)-\frac{\lambda}{v}+\frac{p_{1}}{v}
\end{aligned}
$$

Therefore, Hamiltonian function is maximized by the following values of $u_{t r}$ and $u_{b r}$

$$
\begin{aligned}
& u_{t r}=1 \text { if } p>1 \\
& u_{t r} \in[0,1] \text { if } p=1 \\
& u_{t r}=0 \text { if } p<1 \\
& u_{b r}=0 \text { if } 0<p<1 \\
& u_{b r} \in[0,1] \text { if } p=0 \\
& u_{b r}=1 \text { if } p<0
\end{aligned}
$$

From the above analysis, five optimal control laws are designed:

Full power (FP): $u_{t r}=1, u_{b r}=0$ when $p>1$

Partial power (PP): (PP) : $u_{t r} \in[0,1], u_{b r}=0$ when $p=1$

Coasting (C): $u_{t r}=0, u_{b r}=0$ when $0<p<1$

Full braking (FB): $u_{t r}=0, u_{b r}=1$ when $p<0$

Partial braking (PB): $u_{t r}=0, u_{b r} \in[0,1]$ when $p=0$

Substitute (16), (19) in (18), finding the differential

equation for $\mathrm{p}(\mathrm{x})$.

$$
\begin{aligned}
& \frac{d p}{d x}=\frac{(1-p)}{v} u_{t r} f_{t r}^{\prime}(v)+\frac{(p-1)}{v^{3}} p_{s c}(t)+\frac{p}{v} u_{b r} f_{b r}^{\prime}(v) \\
& +\frac{p}{v} w_{0}^{\prime}(v)-\frac{\lambda}{v^{3}}-\frac{p_{1}}{v^{3}}
\end{aligned}
$$

Full power mode: $p>1, u_{b r}=0, u_{t r}=1$

finding accelerating time $t_{a}$, accelerating distance $x_{a}$.

Using equation (22)

$$
\frac{d p}{d x}=\frac{(1-p)}{v} f_{t r}^{\prime}(v)+\frac{(p-1)}{v^{3}} p_{s c}(t)+\frac{p}{v} w_{0}^{\prime}(v)-\frac{\lambda}{v^{3}}-\frac{p_{1}}{v^{3}}
$$

From (7) finding the differential equation to determine $x_{a}, t_{a}$ :

$$
\left\{\begin{array}{l}
\frac{d x}{d v}=\frac{v^{2}}{v \cdot u_{t r} f_{t r}(v)+p_{s c}(t)-v \cdot w_{0}(v)-f_{\text {gral }}(x) \cdot v} \\
\frac{d t}{d v}=-\frac{v}{v \cdot u_{t r} f_{t r}(v)+p_{s c}(t)-v \cdot w_{0}(v)-f_{\text {grad }}(x) \cdot v}
\end{array}\right.
$$

With initial conditions: $x(0)=0, t(0)=0$.

Partial Power mode: $p=1, u_{b r}=0,0<u_{t r}<1$, so $\frac{d p}{d x}=0$, finding multiplier $\lambda$. 
Using equation (23):

$$
\frac{1}{v} w_{0}^{\prime}(v)-\frac{\lambda}{v^{3}}-\frac{p_{1}}{v^{3}}=0
$$

Where $v_{h}$ - hold speed is chosen previously.

Easily, from (15), $p_{1}$ is chosen by 0

$$
\text { So } \lambda=v^{2} w_{0}^{\prime}
$$

There, $\lambda=v^{2}(b+2 c v)$

If 1 is chosen previously, solve to find the hold-speed $v_{h}$.

Coasting mode: $u_{t r}=0, u_{b r}=0,0<p<1$; finding braking speed $v_{b}$, coasting time $t_{c}$, coasting distance $x_{c}$. Coasting speed $v_{b}$ is calculated as following $(24,44)$

$$
v_{b}=\frac{\psi\left(v_{h}\right)}{\varphi^{\prime}\left(v_{h}\right)}
$$

Where $\varphi=v \cdot w_{0}(v), \psi=v^{2} \cdot w_{0}^{\prime}(v)$

From (7) finding the differential equation to determine $x_{c}, t_{c}$

$$
\left\{\begin{array}{l}
\frac{d x}{d v}=\frac{v}{-w_{0}(v)-f_{\text {grad }}(x)} \\
\frac{d t}{d v}=-\frac{1}{w_{0}(v)+f_{\text {grad }}(x)}
\end{array}\right.
$$

with $t\left(v=v_{h}\right)=t_{a} ; x\left(v=v_{h}\right)=x_{a}$

Partial braking mode: $u_{t r}=0,0<u_{\text {or }}<1, p=0$, finding.

Using equation (23):

$$
-\frac{1}{v^{3}} p_{s c}(t)-\frac{\lambda}{v^{3}}-\frac{p_{1}}{v^{3}}=0
$$

Therefore, $\lambda=-p_{s c}(t)-p_{1}$

Full braking mode: $u_{t r}=0, u_{b r}=1, p<0$ finding braking time $t_{b}$,braking distance $x_{b}$.

Using equation (23)

$$
\frac{d p}{d x}=\frac{(p-1)}{v^{3}} p_{s c}(t)+\frac{p}{v} f_{b r}^{\prime}(v)+\frac{p}{v} w_{0}^{\prime}(v)-\frac{\lambda}{v^{3}}-\frac{p_{1}}{v^{3}}
$$

From (7) finding the differential equation:

$$
\left\{\begin{aligned}
\frac{d x}{d v} & =\frac{v^{2}}{-v \times u_{b r} f_{b r}(v)-v \times w_{0}(v)+p_{s c}(t)-v \times f_{\text {grad }}(x)} \\
\frac{d t}{d v} & =\frac{1}{u_{b r} f_{b r}(v)-w_{0}(v)+\frac{p_{s c}(t)}{v}-f_{\text {grad }}(x)}
\end{aligned}\right.
$$

with $t\left(v=v_{b}\right)=t_{b}, x\left(v=v_{b}\right)=x_{b}$

\subsection{Control Design For DC-DC Interleaved Converter}

The charge/discharge of SCESS tracking the optimal speed profile is performed by designing controllers based on the principle CMC for DC-DC interleaved converter. CMC is shown in Figure 7 with the dual-loop control structure. 


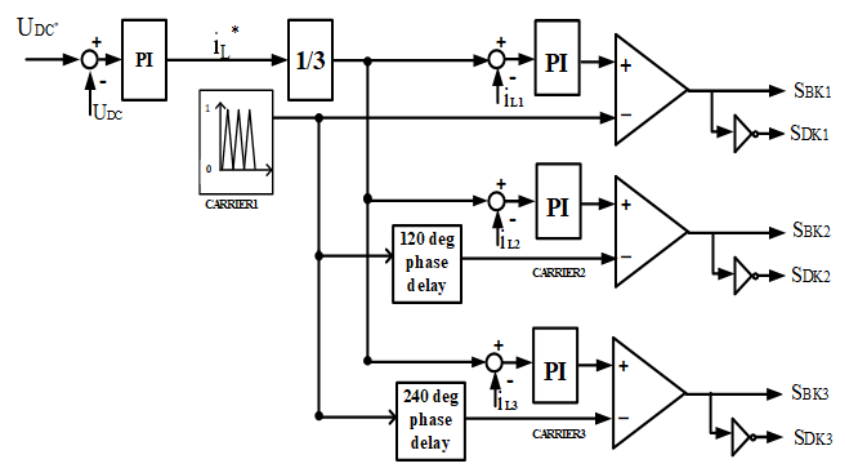

Fig 7. Cascaded loop control structure of the bidirectional DC-DC converter

The inner loop-the current loop captures the inductor current dynamics; namely, managing charge or discharge of supercapacitor system, while the outer loop - the voltage loop is designed to keep DC-link voltage at a certain constant value regardless of the variations of load and input voltage.

\subsubsection{Design of the PI current-loop control algorithm}

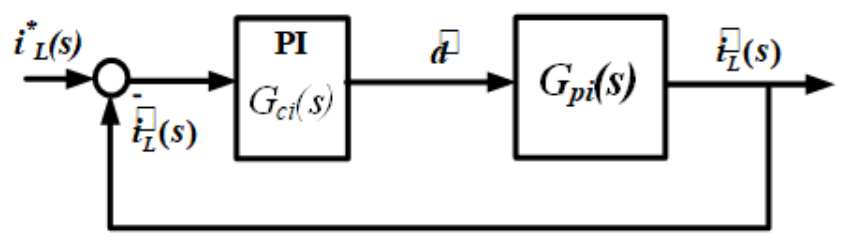

Fig 8. Current-loop control structure

From the first equation of (6), setting

$$
\begin{aligned}
& \frac{d \widetilde{i}_{L}(t)}{d t}=-\frac{R_{L}}{L} \widetilde{i}_{L}(t)+\frac{1}{L}\left(\widetilde{d}(t) U_{D C-\text { linte }}+D \widetilde{u}_{D C-\text { lint }}(t)\right) \\
& -\frac{1}{L} \widetilde{u}_{S C}(t)
\end{aligned}
$$

In steady state, $u_{s c}$ may be considered as constant and therefore acts as constant disturbance for the control loop. It can be compensated by feed-forward control.

Therefore, the transfer function relating the inductor current with the duty cycle $\mathrm{d}(\mathrm{t})$ is computed:

$$
G_{p i}(s)=\frac{\tilde{i}_{L}(s)}{\tilde{d}(s)}=\frac{U_{D C-l i n h} / R_{L}}{\left(\frac{L}{R_{L}} s+1\right)}=\frac{k}{T s+1}
$$

Where $k=\frac{U_{D C-\text { linke }}}{R_{L}}, T=\frac{L}{R_{L}}$.

The corresponding PI current controller transfer function is given by:

$$
G_{p i}(s)=\frac{\tilde{i}_{L}(s)}{\tilde{d}(s)}=\frac{U_{D C-l i n h} / R_{L}}{\left(\frac{L}{R_{L}} s+1\right)}=\frac{k}{T s+1}
$$

The closed-loop transfer function is shown in (38)

$$
G_{S i}(s)=\frac{1+T_{I} s}{\left(T_{I I} T / k_{p i} k\right) s^{2}+T_{I i}\left[1+\left(1 / k_{p} k\right)\right] s+1}
$$


A first-order transfer function with the gain equal to 1 is stable, having static error equal to 0 and short transient process if inertia time constant is small, so authors determined in order to closed-transfer function (38) can be defined as (39):

$$
G_{S i}(s)=\frac{1+T_{I i} s}{\left(T_{I i} T / k_{p i} k\right) s^{2}+T_{I i}\left[1+\left(1 / k_{p} k\right)\right] s+1} \square \frac{1}{T^{\prime} s+1}
$$

Where T' - the smaller is the better

The best PI controller performance was gained when the plant's dominant pole was cancelled by the controller (39).

Thus, the zero at $-\frac{1}{T_{I i}}$ was assigned to the time constant of the plant, which was $T_{I i}=T=\frac{L}{r_{L}}$, and $\frac{T}{k_{p i} k}=2 \times 10^{-4}(s)$, so $T_{I i}=$ $\frac{L}{R_{L}}, k_{p i}=\frac{L \times 10^{4}}{2 \times U_{D C-\text { inke }}}$

\subsubsection{Design of the PI voltage-loop control algorithm}

For the small perturbations, the current loop acts extremely fast, and it can be assumed ideally with a gain of unity.

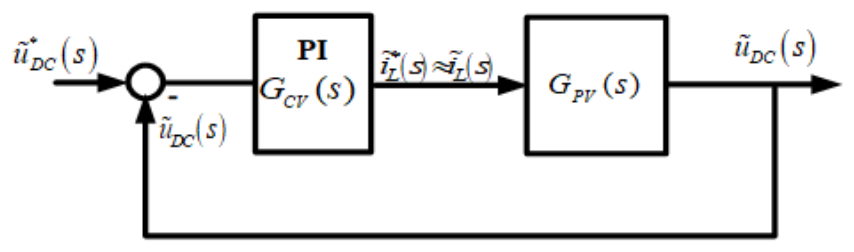

Fig 9. Voltage-loop control structure

Form the second equation of (6) the transfer function relating the voltage $\mathrm{u}_{\text {DClink }}$ with the inductor current is computed:

$$
\begin{gathered}
\frac{d \widetilde{u}_{D C_{-} \text {link }}(t)}{d t}=\frac{1}{C}{\widetilde{i_{\text {inv }}}}(t)-\frac{1}{C} \cdot \frac{U_{\text {sce }}}{U_{D C_{-} \text {linke }}} \widetilde{i_{L}}(t)-\frac{1}{C} \cdot d(t) \cdot I_{L e} \\
G_{V i}(s)=\frac{\widetilde{u}_{D C-\text { link }}(s)}{\widetilde{i}_{L}(s)}=\frac{U_{\text {sce }}}{C U_{D C_{-} \text {linke }} S}=\frac{K_{u}}{s}
\end{gathered}
$$

With $K_{u}=\frac{U_{s c e}}{C U_{D C} \text { linke }}$

The transfer function of outer loop is type of the integral form. However, the system still exists disturbance, so digital PI controller may be effectively used to ensure both zero steady-state error and controlled bandwidth.

The transfer function of PI

$$
G_{c v}(s)=k_{p v}\left(1+\frac{1}{T_{i v} s}\right)
$$

The closed- loop transfer function of Figure 9 is shown:

$$
\begin{aligned}
G_{k i n_{-} \mathrm{da}}(s) & =\frac{G_{C V}(s) G_{P V}(s)}{1+G_{C V}(s) R_{P V}(s)} \\
& =\frac{k_{1} T_{I V} \cdot s+k_{1}}{s^{2}+k_{1} T_{I V} \cdot s+k_{1}}
\end{aligned}
$$

Using Symmetry Optimal Method with norm function finds values of $k_{P V}, T_{I V}$

$$
F_{k l}(s)=\frac{k_{1} \cdot T_{V} \cdot s+k_{1}}{s^{2}+k_{1} \cdot T_{I V} \cdot s+k_{1}} \square \frac{2 . \xi \cdot \omega_{n} \cdot s+\omega_{n}^{2}}{s^{2}+2 \cdot \xi \cdot \omega_{n} \cdot s+\omega_{n}^{2}}
$$

Where $w_{n}$ - Oscillation cycle, $\mathrm{x}$ - Damping ratio (select $\left.\mathrm{x}=0.71\right)$

$$
\Rightarrow\left\{\begin{array} { l } 
{ k _ { 1 } = \omega _ { n } ^ { 2 } } \\
{ k _ { 1 } T _ { I V } = 2 . \xi . \omega _ { n } }
\end{array} \Leftrightarrow \left\{\begin{array} { l } 
{ k _ { 1 } = \frac { k _ { P V } \cdot k _ { u } } { T _ { I V } } = \omega _ { n } ^ { 2 } } \\
{ T _ { I V } = \frac { 2 . \xi \omega _ { n } } { \omega _ { n } ^ { 2 } } = \frac { 2 . \xi } { \omega _ { n } } }
\end{array} \Leftrightarrow \left\{\begin{array}{l}
k_{P V}=-\frac{\omega_{n}^{2} T_{i u} \cdot C U_{D C_{-} \text {linke }}}{U_{\text {sce }}} \\
T_{I V}=\frac{2 . \xi}{\omega_{n}}
\end{array}\right.\right.\right.
$$




\section{Simulation Result and Analysis}

To verify the effectiveness of the control strategy, a simulation is formulated. The train parameters and line in the simulation are based on the data of Cat Linh-Ha Dong metro line, Vietnam. There are 12 stations, 01 depot, 06 traction substations, and two-side power supply mode ${ }^{(45)}$.

Table 1. Train parameters of Metro line Cat Linh - Ha Dong.

\begin{tabular}{lll}
\hline Parameters of metro train & Unit & Value \\
\hline Train formation & $2 \mathrm{M} 2 \mathrm{~T}$ & 08 \\
Number of electrical traction units & & $0.94 / 1$ \\
Max acceleration/braking rates & $\mathrm{km} / \mathrm{h}$ & 80 \\
Maximum speed & $\mathrm{km} / \mathrm{h}$ & 32 \\
Base speed & & \\
\hline
\end{tabular}

Table 2. Route data from Cat Linh to La Thanh station

\begin{tabular}{lll}
\hline Parameters of route & Unit & Value \\
\hline Length of simulation route & $\mathrm{m}$ & 12661 \\
Running time & 992 \\
& $a=1.19 \times 10^{-2}$ \\
David's coefficients of train's resistance & $b=2.56 \times 10^{-3}$ \\
& $c=1.54 \times 10^{-4}$ \\
\hline
\end{tabular}

Table 3. Simulation parameters of train

\begin{tabular}{lll}
\hline Parameters of metro train & unit & value \\
\hline Train gand-up & $2 \mathrm{M} 2 \mathrm{~T}$ & 246700 \\
Full load translating mass & {$[\mathrm{kg}]$} & 08 \\
Number of electrical traction unit $(\mathrm{N})$ & $\mathrm{km} / \mathrm{h}$ & 80 \\
Max speed $\left(\mathrm{V}_{\max }\right)$ & $\mathrm{km} / \mathrm{h}$ & 40 \\
Base speed $\left(\mathrm{V}_{b}\right)$ & & 30 \\
Dwell time & $\mathrm{m} / \mathrm{s}^{2}$ & $0.94 / 1$ \\
Max acceleration/braking rates & {$[\mathrm{m}]$} & 0.84 \\
Wheel diameter $\left(\mathrm{D}_{\text {wh }}\right)$ & & \\
Parameters of super-capacitor BMOD0063 P125 B08 63F/125V & \\
\hline
\end{tabular}

Operation modes of electrified train includes: Accelerating (R) Coasting (R) Braking.

Depending on track conditions, constraints, the speed from a station to another station is different, but it is always smaller than limit speed $80 \mathrm{~km} / \mathrm{h}$. While the train runs in Optimal speeds slower than in original ones from 1 to $3 \mathrm{~km} / \mathrm{h}$, optimal switching points change, so do optimal accelerating, coasting, braking distances significantly, but keeping running time unchanged as in Figures 11 and 12. Tables 4 and 5 show that saving energy for train operation in optimal speed trajectory applied PMP up to $10.15 \%$ in comparison with original speed trajectory, level of energy saving if combining two solutions PMP and SCESS increases up to $14.7 \%$, higher than that of energy saving of original speed only using PMP.

When the train operates in braking phase, surplus energy is absorbed by SCESS, and this kind of energy which is released to support the train in accelerating phase is represented by supercapacitor power shown Figure 10 . In Figure 10 described discharge/charge process of SCESS from Cat Linh to La Thanh station (with other stations, discharge/charge process of SCESS is similar). The SCESS can discharge energy in $32 \mathrm{~s}$ (from 0 to 32th second) with equal to -225kW, the SESS does not charge/ discharge within $31 \mathrm{~s}$ of coasting phase (from 33th second to 63th second), and charge in regenerative braking phase in 16s (from 63th second to 79th second) with equal to $447 \mathrm{~kW}$. From $80^{\text {th }}$ second to $88^{\text {th }}$ second, electric train speed is slower than $10 \mathrm{~km} / \mathrm{h}$, so the regenerative braking energy is not recuperated. 


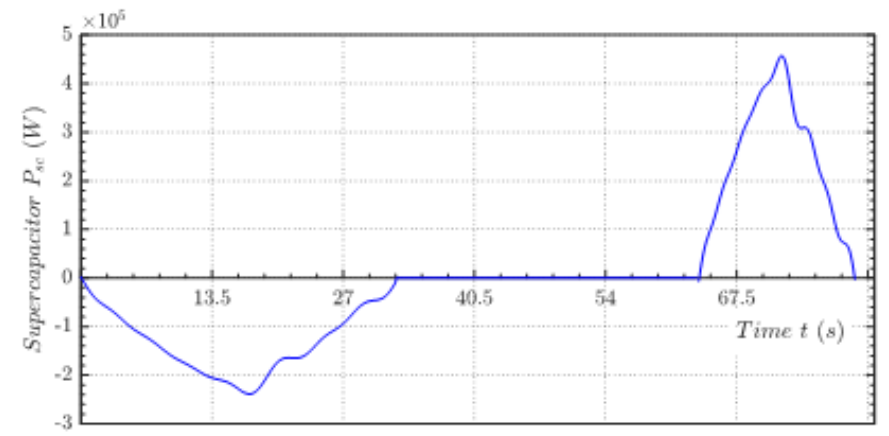

Fig 10. Discharge/charge power of supercapacitor energy storage system

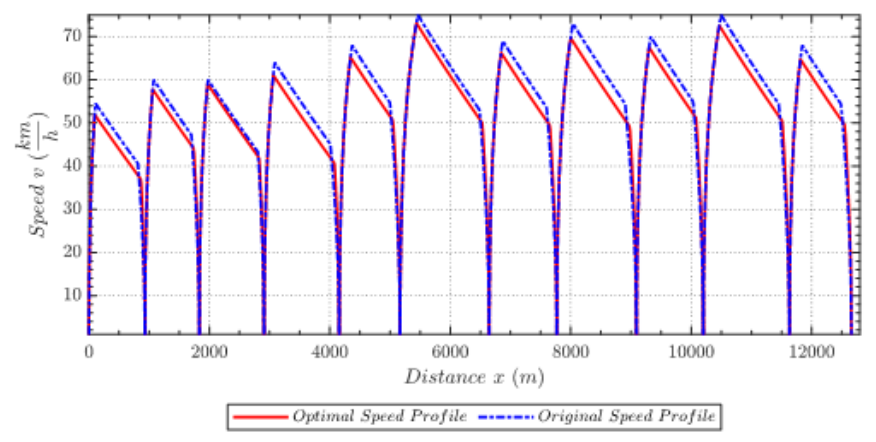

Fig 11. A Comparison of Optimal speed profile and original speed profile

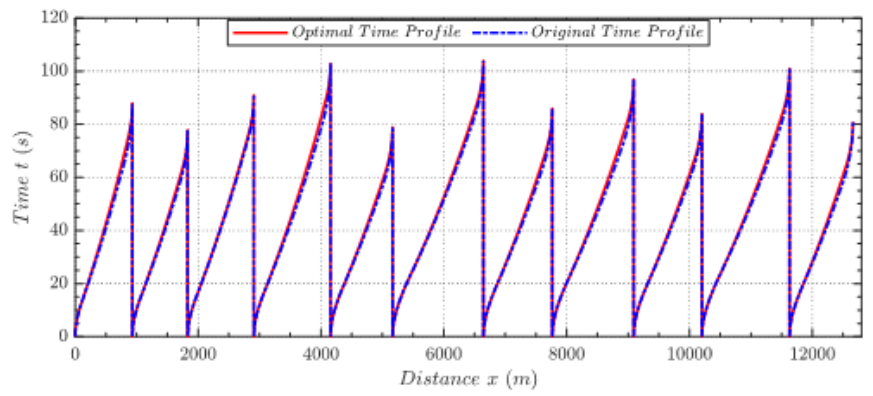

Fig 12. A Comparison of Optimal time profile and original time profile without dwell time

Table 4. Results of a comparison of energy consumption with/ without PMP

\begin{tabular}{|c|c|c|c|c|c|}
\hline Inter-station length & $\begin{array}{l}\text { Distance } \\
(\mathrm{m})\end{array}$ & $\begin{array}{l}\text { Trip time } \\
\text { (s) }\end{array}$ & $\begin{array}{l}\text { Practical energy con- } \\
\text { sumption (kWh) }\end{array}$ & $\begin{array}{l}\text { Energy consumption opti- } \\
\text { mization applied PMP (kWh) }\end{array}$ & $\begin{array}{l}\text { Energy } \\
\text { saving (\%) }\end{array}$ \\
\hline Cat Linh-La Thanh & 931 & 88 & 8.31 & 7.50 & 9.75 \\
\hline La Thanh-Thai Ha & 902 & 78 & 10.20 & 9.40 & 7.84 \\
\hline Thai Ha-Lang & 1076 & 91 & 10.20 & 9.86 & 3.33 \\
\hline Lang-Thuong Dinh & 1248 & 103 & 11.73 & 10.60 & 9.63 \\
\hline Thuong Dinh- Ring Road 3 & 1010 & 79 & 13.41 & 12.23 & 8.80 \\
\hline Ring Road 3-Phung Khoang & 1480 & 104 & 16.75 & 15.82 & 5.55 \\
\hline Phung Khoang-Van Quan & 1121 & 86 & 13.85 & 12.66 & 8.59 \\
\hline Van Quan- Ha Dong & 1324 & 97 & 15.74 & 14.17 & 9.97 \\
\hline Ha Dong-La Khe & 1110 & 84 & 14.30 & 13.18 & 7.83 \\
\hline La Khe-Van Khe & 1428 & 101 & 16.75 & 15.53 & 7.28 \\
\hline Van Khe-Yen Nghia & 1032 & 81 & 13.40 & 12.04 & 10.15 \\
\hline
\end{tabular}


Table 5. Results of a comparison of energy consumption with / without energy optimal solutions (PMP and SCESS)

\begin{tabular}{lllllc}
\hline Inter-station length & $\begin{array}{l}\text { Distance } \\
(\mathrm{m})\end{array}$ & $\begin{array}{l}\text { Trip time } \\
(\mathrm{s})\end{array}$ & $\begin{array}{l}\text { Practical energy con- } \\
\text { sumption (kWh) }\end{array}$ & $\begin{array}{l}\text { Energy consumption optimiza- } \\
\text { tion applied PMP and onboard- } \\
\text { SCESS (kWh) }\end{array}$ & $\begin{array}{l}\text { Energy saving } \\
(\%)\end{array}$ \\
\hline Cat Linh-La Thanh & 931 & 88 & 8.31 & 7.16 & 13.84 \\
La Thanh-Thai Ha & 902 & 78 & 10.20 & 9.91 & 12.65 \\
Thai Ha-Lang & 1076 & 91 & 10.20 & 9.41 & 7.75 \\
Lang-Thuong Dinh & 1248 & 103 & 11.73 & 10.18 & 13.21 \\
Thuong Dinh- Ring Road 3 & 1010 & 79 & 13.41 & 15.19 & 13.57 \\
Ring Road 3-Phung Khoang & 1480 & 104 & 16.75 & 12.05 & 13.31 \\
Phung Khoang-Van Quan & 1121 & 86 & 13.85 & 13.57 & 13.00 \\
Van Quan- Ha Dong & 1324 & 97 & 15.74 & 12.54 & 13.79 \\
Ha Dong-La Khe & 1110 & 84 & 14.30 & 14.90 & 12.31 \\
La Khe-Van Khe & 1428 & 101 & 16.75 & 11.43 & 11.04 \\
Van Khe-Yen Nghia & 1032 & 81 & 13.40 & 14.70 \\
\hline
\end{tabular}

\section{Conclusion}

The paper proposed two integrated solutions to minimize total input energy of metro network: using the optimal speed profiles and onboard-SCESS with charging/discharging processes tracking the optimal speed profile. The simulation results with studied cases for Cat Linh - Ha Dong metro line, Vietnam show that the biggest saving energy of trains' operation tracking the optimal speed profile is the highest about 10\%, while if applying both solutions (tracking optimal speed profiles, and recovering regenerated braking energy by SCESS), energy saving increases significantly to $14.7 \%$. Furthermore, this paper also has provided the foundation research for enhancing levels of energy-efficient operation by applying integrated energy saving methods which are feasible and efficient in Urban railways of Vietnam in the near future.

\section{References}

1) Yang X, Li X, Ning B, Tang T. A survey on energy-efficient train operation for urban rail transit. IEEE Transactions on Intelligent Transportation Systems. 2015;17(1):2-13. Available from: https://doi.org/10.1109/TITS.2015.2447507.

2) González-Gil A, Palacin R, Batty P, Powell JP. A systems approach to reduce urban rail energy consumption. Energy Conversion and Management. 2014;80:509-524. Available from: https://dx.doi.org/10.1016/j.enconman.2014.01.060.

3) Barrero R, Mierlo JV, Tackoen X. Energy savings in public transport. IEEE Vehicular Technology Magazine. 2008;3:26-36. Available from: https: //dx.doi.org/10.1109/mvt.2008.927485.

4) Allegre AL, Bouscayrol A, Delarue P, Barrade P, Chattot E, El-Fassi S. Energy Storage System With Supercapacitor for an Innovative Subway. IEEE Transactions on Industrial Electronics. 2010;57(12):4001-4012. Available from: https://dx.doi.org/10.1109/tie.2010.2044124.

5) Iannuzzi D, Tricoli P. Speed-Based State-of-Charge Tracking Control for Metro Trains With Onboard Supercapacitors. IEEE Transactions on Power Electronics. 2012;27(4):2129-2140. Available from: https://dx.doi.org/10.1109/tpel.2011.2167633.

6) Ciccarelli F, Iannuzzi D, Tricoli P. Control of metro-trains equipped with onboard supercapacitors for energy saving and reduction of power peak demand. Transportation Research Part C: Emerging Technologies. 2012;24:36-49. Available from: https://dx.doi.org/10.1016/j.trc.2012.02.001.

7) Domínguez M, Fernández A, Cucala AP, Lukaszewicz P. Optimal design of metro automatic train operation speed profiles for reducing energy consumption. Proceedings of the Institution of Mechanical Engineers, Part F: Journal of Rail and Rapid Transit. 2011;225:463-474. Available from: https://dx.doi.org/10.1177/09544097jrrt420.

8) Steiner M, Klohr M, IEEE SP. Energy storage system with ultracaps on board of railway vehicles. In: 2007 European conference on power electronics and applications. 2007;p. 1-10. Available from: https://doi.org/10.1109/EPE.2007.4417400.

9) Schroeder MP, Yu J, Teumim D. Guiding the Selection and Application of Wayside Energy Storage Technologies for Rail Transit and Electric Utilities. In: National Academies of Sciences, Engineering, and Medicine. 2010. 2010. Available from: https://doi.org/10.17226/22911.

10) Barrero R, Tackoen X, Mierlo JV. Analysis and configuration of supercapacitor based energy storage system on-board light rail vehicles. 13th International Power Electronics and Motion Control Conference. 2008;p. 1512-1517. Available from: https://doi.org/10.1109/EPEPEMC.2008.4635481.

11) Battistelli L, Ciccarelli F, Lauria D, Proto D. Optimal design of DC electrified railway stationary storage system. International Conference on Clean Electrical Power. 2009;p. 739-745. Available from: https://doi.org/10.1109/ICCEP.2009.5211971.

12) Iannuzzi D, Ciccarelli F, Lauria D. Stationary ultracapacitors storage device for improving energy saving and voltage profile of light transportation networks. Transportation Research Part C: Emerging Technologies. 2012;21:321-337. Available from: https://dx.doi.org/10.1016/j.trc.2011.11.002.

13) Teymourfar R, Asaei B, Iman-Eini H, fard RN. Stationary super-capacitor energy storage system to save regenerative braking energy in a metro line. Energy Conversion and Management. 2012;56:206-214. Available from: https://dx.doi.org/10.1016/j.enconman.2011.11.019.

14) Teymourfar R, Farivar G, Iman-Eini H, Asaei B. Optimal stationary super-capacitor energy storage system in a metro line. 20112 nd International Conference on Electric Power and Energy Conversion Systems (EPECS). 2011;p. 1-5. Available from: https://doi.org/10.1109/EPECS.2011.6126828.

15) Khodaparastan M, Mohamed A. A study on super capacitor wayside connection for energy recuperation in electric rail systems. IEEE Power \& Energy Society General Meeting. 2017;p. 1-5. Available from: https://doi.org/10.1109/PESGM.2017.8273915. 
16) Somasundaram D, S B. A closed loop control of quadratic boost converter using pid controller. International Journal of Engineering. 2014;27(11):1653-62. Available from: 10.5829/idosi.ije.2014.27.11b.02.

17) Cornic D. Efficient recovery of braking energy through a reversible dc substation. In: Electrical systems for aircraft, railway and ship propulsion. IEEE. 2010;p. 1-9. Available from: https://doi.org/10.1109/ESARS.2010.5665264.

18) Ibaiondo H, Romo A. Kinetic energy recovery on railway systems with feedback to the grid. Proceedings of 14th International Power Electronics and Motion Control Conference EPE-PEMC. 2010;p. 9-94. Available from: https://doi.org/10.1109/EPEPEMC.2010.5606545.

19) Albrecht $T$. Reducing power peaks and energy consumption in rail transit systems by simultaneous train running time control. WIT Transactions on State-of-the-art in Science and Engineering. 2010. Available from: 10.2495/CR040881.

20) Nasri A, Moghadam MF, Mokhtari H. Timetable optimization for maximum usage of regenerative energy of braking in electrical railway systems. SPEEDAM 2010. 2010;p. 1218-1221. Available from: https://doi.org/10.1109/SPEEDAM.2010.5542099.

21) Peña-Alcaraz M, Fernández A, Cucala AP, Ramos A, Pecharromán RR. Optimal underground timetable design based on power flow for maximizing the use of regenerative-braking energy. Proceedings of the Institution of Mechanical Engineers, Part F: Journal of Rail and Rapid Transit. 2012;226:397-408. Available from: https://dx.doi.org/10.1177/0954409711429411.

22) Fathy A, Yousri D, Alanazi T, Rezk H. Minimum hydrogen consumption based control strategy of fuel cell/PV/battery/supercapacitor hybrid system using recent approach based parasitism-predation algorithm. Energy. 2021;225(120316). Available from: https://dx.doi.org/10.1016/j.energy.2021.120316.

23) Jamadar NM, Jadhav HT. A review on braking control and optimization techniques for electric vehicle. Proceedings of the Institution of Mechanical Engineers, Part D: Journal of Automobile Engineering. 2021. Available from: https://dx.doi.org/10.1177/0954407021996906.

24) Yang J, Jia L, Lu S, Fu Y, Ge J. Energy-Efficient Speed Profile Approximation: An Optimal Switching Region-Based Approach with Adaptive Resolution. Energies. 2016;9:762. Available from: https://dx.doi.org/10.3390/en9100762.

25) Foumani MS, Delkhosh M. Modification of Equivalent Consumption Minimization Strategy for a Hybrid Electric Vehicle. International Journal of Engineering. 2016;29(12):1757-1764. Available from: 10.5829/idosi.ije.2016.29.12c.15.

26) Khoi TV, Khuong ND. Optimal planning of substations on urban railway power supply systems using integer linear programming. Transport and Communications Science Journal. 2019;70(4):264-278. Available from: http://dx.doi.org/10.25073/tcsj.70.4.4.

27) Howlett P. The optimal control of a train. Annals of Operations Research. 2000;98:65-87. Available from: https://doi.org/10.1023/A:1019235819716.

28) Howlett PG, Pudney PJ. Energy-efficient train control. Springer Science \& Business Media. 2012. Available from: https://doi.org/10.1007/978-1-44713084-0.

29) Vu X. Analysis of Necessary Conditions for the Optimal Control of a Train: New Necessary Conditions for Energy-Efficient Train Control . . Available from: https://www.amazon.com/Analysis-necessary-conditions-optimal-control/dp/3639120000.

30) Albrecht A, Howlett P, Pudney P, Vu X, Zhou P. The key principles of optimal train control-Part 1: Formulation of the model, strategies of optimal type, evolutionary lines, location of optimal switching points. Transportation Research Part B: Methodological. 2016;94:482-508. Available from: https://dx.doi.org/10.1016/j.trb.2015.07.023.

31) Albrecht A, Howlett P, Pudney P, Vu X, Zhou P. The key principles of optimal train control-Part 2: Existence of an optimal strategy, the local energy minimization principle, uniqueness, computational techniques. Transportation Research Part B: Methodological. 2016;94:509-538. Available from: https://dx.doi.org/10.1016/j.trb.2015.07.024.

32) Khmelnitsky E. On an optimal control problem of train operation. IEEE Transactions on Automatic Control. 2000;45(7):1257-1266. Available from: https://dx.doi.org/10.1109/9.867018.

33) Liu RR, Golovitcher IM. Energy-efficient operation of rail vehicles. Transportation Research Part A: Policy and Practice. 2003;37:917-932. Available from: https://dx.doi.org/10.1016/j.tra.2003.07.001.

34) Nguyễn BH, Vo-Duy T, Ta MC, Trovão JP. Optimal Energy Management of Hybrid Storage Systems Using an Alternative Approach of Pontryagin’s Minimum Principle. IEEE Transactions on Transportation Electrification. 2021. Available from: https://doi.org/10.1109/TTE.2021.3063072.

35) Lu S, Hillmansen S, Ho TK, Roberts C. Single-Train Trajectory Optimization. IEEE Transactions on Intelligent Transportation Systems. 2013;14(2):743-750. Available from: https://dx.doi.org/10.1109/tits.2012.2234118.

36) Domínguez M, Fernández A, Cucala AP, Cayuela LP. Computer-aided design of ATO speed commands according to energy consumption criteria. WIT Transactions on the Built Environment. 2008;103:183-192. Available from: 10.2495/978-1-84564-498-7/06.

37) Wong KK, Ho TK. Dynamic coast control of train movement with genetic algorithm. International Journal of Systems Science. 2004;35(13-14):835-846. Available from: https://dx.doi.org/10.1080/00207720412331203633.

38) Açıkbaş S, Söylemez MT. Coasting point optimisation for mass rail transit lines using artificial neural networks and genetic algorithms. IET Electric Power Applications. 2008;2:172-182. Available from: https://dx.doi.org/10.1049/iet-epa:20070381.

39) Tuan DD, Toan ND. Developing a program to calculate the unit resultant force of trains on Vietnam railways. Transport and Communications Science Journal. 2020;71(8):907-923. Available from: https://doi.org/10.47869/tcsj.71.8.3.

40) Tiem NV. Speed control for the train of urban railway using fuzzy-d controller. Transport and Communications Science Journal. 2020;71(6):640-650. Available from: https://doi.org/10.25073/tcsj.71.6.1.

41) Sun X, Lu H, Dong H. Energy-efficient train control by multi-train dynamic cooperation. IEEE Transactions on Intelligent Transportation Systems. 2017;18(11):3114-3135. Available from: https://doi.org/10.1109/TITS.2017.2682270.

42) Davis WJ. The tractive resistance of electric locomotives and cars. General Electric. 1926. Available from: https://www.amazon.com/tractive-resistanceelectric-locomotives-cars/dp/B00087UUWS.

43) Tuan AP, Phuong VH, Quang NP. Modeling and Control of Supercapacitor Energy Storage Systems. Journal of Science and Technology Technical Universities. 2014;103.

44) Hai NT. Evaluation of effect Pontryagin's Maximum Principle for optimal control train by criteria of energy save. 2010 International Symposium on Computer, Communication, Control and Automation (3CA) 2010 May 5;1:363-366. Available from: https://doi.org/10.1109/3CA.2010.5533807.

45) Chau NTM. Hanoi Urban Railway Project Cat Linh-Ha Dong Line. Package 1: EPC Contact. . 